\title{
Chamber corrosion inhibitor of zinc plated steel IFKhAN-154
}

\author{
A.Yu. Luchkin, ${ }^{1}(\mathbb{D})$ O.S. Byvsheva, ${ }^{1,2}$ O.A. Goncharova, ${ }^{1}[$ \\ N.N. Andreev ${ }^{1} \mathbb{1} *$ and S.S. Vesely ${ }^{1}$
}

${ }^{1}$ A.N. Frumkin Institute of Physical Chemistry and Electrochemistry, Russian Academy of Sciences, Leninsky pr. 31, 119071 Moscow, Russian Federation

${ }^{2}$ D. Mendeleev University of Chemical Technology of Russia, Miusskaya sq. 9, 125047

Moscow, Russian Federation

*E-mail: $\underline{\text { n.andreev@mail.ru }}$

\begin{abstract}
A combination of methods (voltammetry, electrochemical impedance spectroscopy, and salt fog chamber) was used to study the corrosion and electrochemical behavior of zinc plated steel treated in the vapors of the IFKhAN-154 inhibitor. It was found that IFKhAN-154 efficiently inhibited corrosion by slowing down the anodic dissolution of zinc and stabilizing its passive state. The optimum temperature of chamber treatment (CT) with IFHAN-154 is $100^{\circ} \mathrm{C}$. Chamber treatment at lower or higher temperatures decreases the protective aftereffect of the adsorption films formed by the inhibitor. IFKhAN-154 was shown to be an inhibitor with mixed activation-blocking action. The surface films formed during the chamber treatment of zinc plated steel have a self-organization capability. Exposure of samples in air after chamber treatment results in an increase in the protective ability of the surface layers. The data obtained allow us to assume the following general picture of the chamber protection of zinc plated steel. During its chamber treatment, the inhibitor is physically adsorbed on the sample surface. As a liquid acid, IFKhAN-154 begins to react with the surface oxide and with zinc itself. This process results in poorly soluble salts that ensure metal protection. The reaction continues when the samples are kept in air after the completion of the CT. It is accompanied by changes in the thickness and uniformity of the coating, as well as an increase in the protective properties of the surface films. In about a day, IFKhAN-154 present on the surface is exhausted, and the protective effect of the surface layers ceases to grow.
\end{abstract}

Keywords: zinc plated steel, corrosion, chamber treatment, corrosion inhibitors, IFKhAN154, adsorption films, self-organization.

Received: May 1, 2021. Published: May 7, 2021

doi: $\underline{10.17675 / 2305-6894-2021-10-2-12}$

\section{Introduction}

The field of use of zinc plated steel in the manufacture is huge, from hardware to parts of aerospace vehicles. A zinc layer on steel surface provides excellent anti-corrosion protection of the substrate metal due to a sufficiently large thickness, continuity, and sacrificial action [1]. The latter is possible due to the greater electronegativity of zinc with respect to 
steel. Because of that, steel corrosion is not initiated even in coating defects (chips, scratches) [2].

By itself, zinc that composes a coating can undergo oxidation to give a dense layer of oxides on the surface, which reduces the rate of its corrosion. However, pollution of the atmosphere and hydrosphere results in a considerable shortening of the service life of zinc plated products $[3,4]$. Under the effect of corrosive components of the environment, "white" corrosion can develop on zinc, which worsens the appearance of products and results in a damage to the substrate metal on prolonged exposure. Thus, increasing the corrosion resistance of zinc coatings is a very important scientific and practical task.

Slowing down the destruction of zinc coatings is reached by surface passivation. In the classical understanding, this is the formation of oxide or salt layers on zinc plated steel that prevent the metal from contacting the corrosive components of the environment. Chromium(VI) salts are the most popular zinc passivators. They make it possible to increase the corrosion resistance of zinc and zinc-based coatings by a factor of 8-10 [5, 6]. However, the modern environmental regulations prohibit the use of chromium(VI) compounds because they are very toxic [7].

In recent decades, phosphating and chromitizing processes that are safer for humans and the environment were developed as an alternative to chromating [8]. Chromite coatings are often filled with organic components (ShchIT, Tsinkolak, Barrier-001). Such coatings are not inferior to chromate ones in terms of protective effect and are widely used in modern industry. However, zinc plated items cannot be passivated using such methods if further technological operations require soldering or molding with plastics.

The so-called chamber treatment (CT) [9] is one of the actively developing approaches of temporary protection of metals from corrosion. It is a variety of vapor-phase inhibitor protection. It involves a short-term exposure of metal items in the vapors of corrosion inhibitors (chamber inhibitors, CIN) that have low volatility under ordinary conditions, in a sealed space at an elevated temperature. During CT, nanosized adsorption films that efficiently protect a metal from corrosion are formed on the metal surface.

The advantages of CT as a method of temporary protection include:

- the consumption of an inhibitor is very small;

- no waste is formed so treatment plants are not loaded;

- items do not have to be depreserved;

- products of any configuration, including those with blind holes, can be treated;

- environmental safety - the CIN are present only in a working chamber.

Previously [10-15], we have shown that it is possible to use CIN for the protection of various metals, including zinc, from atmospheric corrosion. This work is the second publication in a series dealing with the creation of CIN for the protection of zinc plated steel. Here we studied the IFKhAN-154 chamber inhibitor, which is a liquid organic acid that proved to be an efficient inhibitor of zinc corrosion [15]. 


\section{Experimental}

Specimens made of St3 steel with $50 \times 30 \times 1 \mathrm{~mm}$ dimensions, with a hole for mounting in the chambers, were used for testing. The samples were abraded on emery wheels with a grain size of P180-P1000 and degreased, then coated with zinc.

Zinc plating of steel samples was carried out in the electrolyte containing:

- zinc chloride: $40-50 \mathrm{~g} / \mathrm{L}$;

- potassium chloride: $210-230 \mathrm{~g} / \mathrm{L}$;

- boric acid: $15-25 \mathrm{~g} / \mathrm{L}$;

- Ecomet zinc 31A brightening additive: $18-25 \mathrm{~g} / \mathrm{L}$;

- Ecomet zinc 31B brightening additive: $18-25 \mathrm{~g} / \mathrm{L}$.

The working current density was $1.5 \mathrm{~A} / \mathrm{dm}^{2}$. The zinc plating time was 20 minutes. As a result, a galvanic coating with a thickness of 12-15 microns (designated Ts12 according to GOST (USSR State Standard) 9.306-85 [16]) was formed on steel.

CT was performed at temperatures $(t)$ from 40 to $120^{\circ} \mathrm{C}$. Zinc plated steel samples were degreased and mounted in sealed glass vessels with a capacity of 0.6 liters containing a weighed amount of the CIN ( $0.5 \mathrm{~g})$ or without it. The vessels were placed in a SNOL 50/350 drying oven heated to a required temperature. The CT duration was 1 hour. Data reported previously [15] indicate that this amount of time is sufficient to form adsorption films with an equilibrium thickness on the samples. After exposure in the drying oven, the vessels were removed and cooled to room temperature. The samples were removed from the atmosphere containing the CIN vapors and kept under ambient conditions, then used in the tests.

Voltammetric experiments were performed using an IPC-pro potentiostat (Russian Federation) and a clamp-on three-electrode cell. A platinum wire was used as the auxiliary electrode. The potentials $(E)$ were measured against a saturated silver/silver chloride reference electrode and then converted to the normal hydrogen scale. Experiments were carried out in borate buffer solution $(\mathrm{pH} 7.36)$ containing $0.001 \mathrm{M}$ sodium chloride. A clamp-on cell was mounted on a sample; the electrolyte was poured into it and kept for 5 min. The electrode was polarized anodically from the established potential $\left(E_{0}\right)$ at a scan rate of $0.2 \mathrm{mV} / \mathrm{s}$. The protective properties of the CIN were estimated by the shift of the breakdown potential $\left(E_{\mathrm{br}}\right)$ relative to the samples that did not undergo CT $(\Delta E)$. $E_{\mathrm{br}}$ was determined as the potential corresponding to an anodic current density $(i)$ of $4 \mu \mathrm{A} / \mathrm{cm}^{2}$.

Electrochemical impedance spectra were recorded using a potentiostat of the same brand and a frequency response analyzer (FRA) manufactured in the Russian Federation. The experiments were carried out in a cell, on electrodes and under conditions similar to those used in the polarization experiments. The frequency was varied within $0.1-10^{6} \mathrm{~Hz}$. Electrochemical impedance parameters were calculated using the equivalent circuits that are widely employed for various metals and alloys [17-20]. They are demonstrated in Figure 1. 


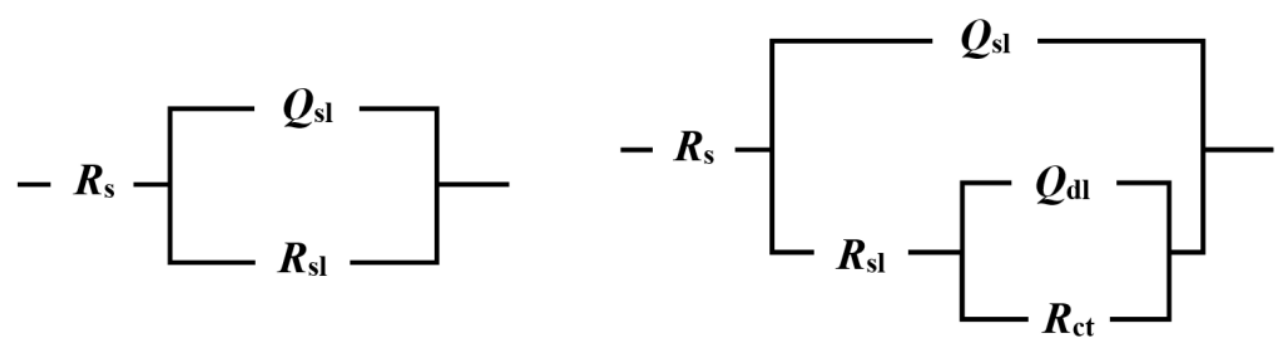

A

B

Figure 1. Equivalent circuits used to describe electrochemical impedance spectroscopy data.

Here $R_{\mathrm{S}}$ is the resistance of the bulk electrolyte between the auxiliary and working electrodes that does not affect the electrode processes and depends on the conductivity of the medium and the cell geometry; $R_{\mathrm{sl}}$ is the resistance of the surface layers (oxide-hydroxide and adsorption ones); $R_{\mathrm{ct}}$ is the polarization resistance characterizing the electrochemical kinetics of the corrosion process; $Q_{\mathrm{sl}}$ is the constant phase element characterizing the capacitance of the surface oxide-hydroxide layers and/or adsorption layers; and $Q_{\mathrm{dl}}$ is the constant phase element that reflects the capacitance of the double electric layer. The constant phase element impedance was described by the equation:

$$
Z_{Q}=A^{-1}(j \omega)^{-n}
$$

where: $A$ is the proportionality factor; $j$ is the imaginary unit; $\omega$ is the complex frequency associated with the alternating current frequency; and $n$ is an exponential indicator of phase deviation, $0 \leq|n| \leq 1$.

The results were processed to determine the equivalent circuit parameters using Dummy Circuits Solver software, version 21. The fit between the experimental and calculated data was no worse than $98 \%$.

The degree of steel electrode protection was calculated by the formula:

$$
Z=\frac{R_{\text {inh }}-R_{\mathrm{bg}}}{R_{\text {inh }}} \cdot 100 \%,
$$

where $R_{\mathrm{bg}}$ and $R_{\text {inh }}$ are the total resistances of the "steel-lectrolyte" interphase interaction that includes $R_{\mathrm{ct}}$ and $R_{\mathrm{sl}}$ after thermal treatment (TT) of the electrode in the absence and in the presence of the CIN, respectively.

Accelerated corrosion tests were carried out in cycles in a neutral salt fog chamber at room temperature. A cycle lasted 1 hour: 15 minutes - spraying a neutral 3\% $\mathrm{NaCl}$ solution, 45 minutes - exposing the samples to the salt fog. During the tests, the time (number of cycles) until the appearance of corrosion on the samples was recorded. The samples were inspected after each test cycle. 


\section{Results and Discussion}

The anodic polarization curves of steel with a Ts12 coating in the initial state, after TT without a CIN, and after CT of electrodes at different $t$ are presented in Figure 2.

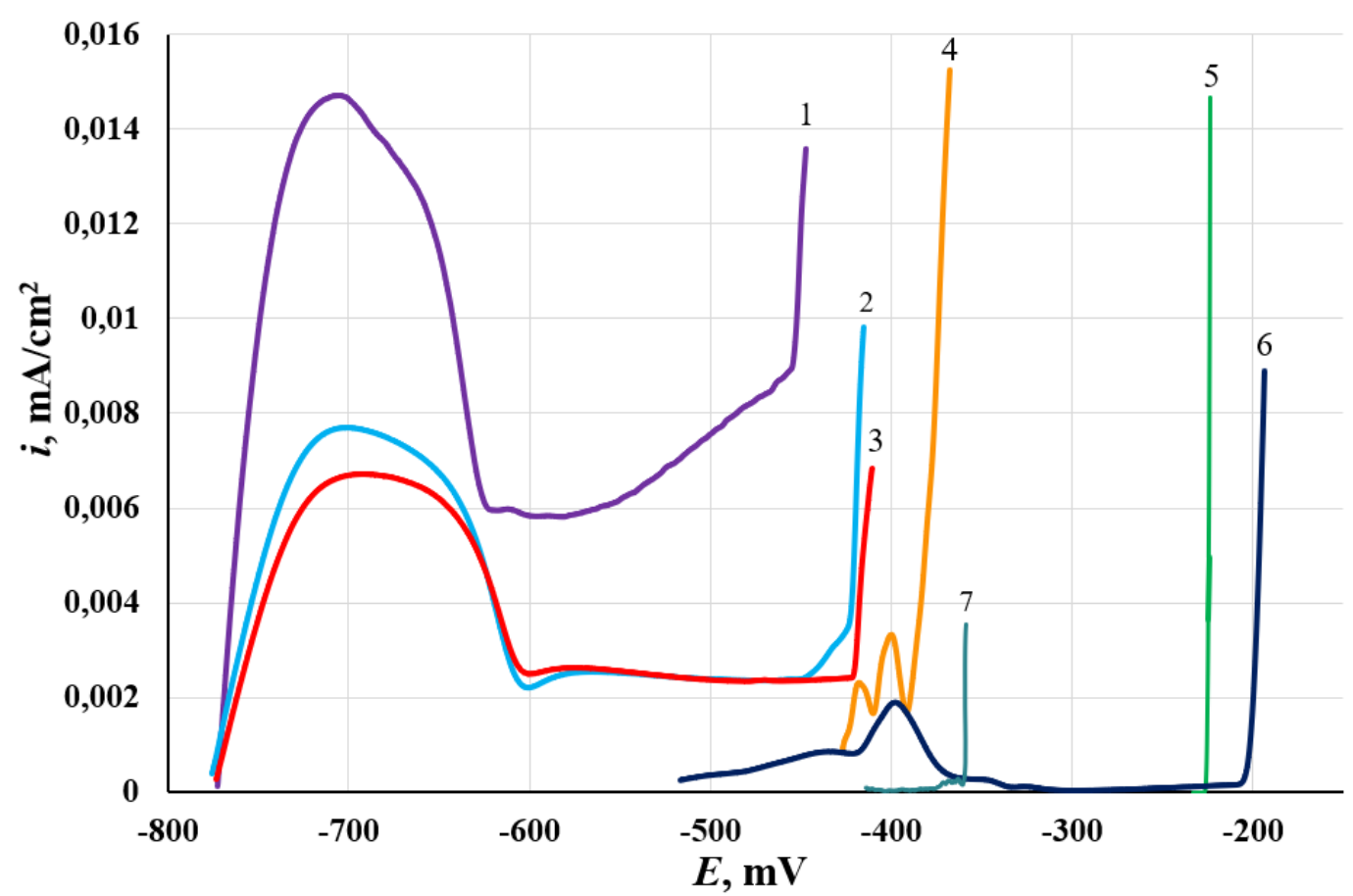

Figure 2. Anodic polarization curves of steel with Ts12 coating in the initial state (1), after TT $\left(100^{\circ} \mathrm{C}\right)$ without a $\mathrm{CIN}(2)$, and after CT in the presence of the $\mathrm{CIN}$ at $40^{\circ} \mathrm{C}(3), 60^{\circ} \mathrm{C}(4)$, $80^{\circ} \mathrm{C}(5), 100^{\circ} \mathrm{C}(6), 120^{\circ} \mathrm{C}(7)$.

The shape of the anodic polarization curves of the Ts12 zinc coating that did not undergo CT resembles that of Ts0 grade zinc [15]. They are characterized by a region of active dissolution, rather a small passivity region, and a sharp increase in $i$ associated with the formation of pits. The lower values of $i$ in the active dissolution region as compared to Ts0 are apparently due to the inclusion of brightening additives in the coating, which have a certain inhibitory effect, during electrodeposition. The main characteristics of the anodic polarization curves of Ts 12 are given in Table 1.

The $E_{0}$ of the electrode with the Ts12 coating in the initial state of such a coating was $-775 \mathrm{mV}$, while the $i$ in the active dissolution region was $14.5 \mu \mathrm{A} / \mathrm{cm}^{2}$. Breakdown of the passive film occurred at $E_{\mathrm{br}}=-455 \mathrm{mV}$.

$\mathrm{TT}$ at $100^{\circ} \mathrm{C}$ without a CIN resulted in a twofold reduction of the active dissolution current. This is most likely due to the growth of the surface oxide during the sample heating, while $E_{\mathrm{br}}$ was slightly ennobled (by $35 \mathrm{mV}$ ) relative to the untreated samples. 
Table 1. Characteristics of the anodic polarization curves of Ts 12 after treatment under various conditions. The treatment time was 1 hour. The exposure time of samples in air after TT or CT was 24 hours.

\begin{tabular}{ccccc}
\hline Treatment conditions & $\boldsymbol{E}_{\mathbf{0}, \mathbf{~} \mathbf{~ V}}$ & $\boldsymbol{i , \mu \mathbf { A } / \mathbf { c m } ^ { \mathbf { 2 } }}$ & $\boldsymbol{E}_{\mathbf{b r}, \mathbf{m V}}$ & $\boldsymbol{\Delta} \boldsymbol{E}, \mathbf{m V}$ \\
\hline Without treatment & -775 & 14.5 & -455 & - \\
TT at $100^{\circ} \mathrm{C}$ without a CIN & -770 & 7.5 & -420 & 35 \\
CT with IFKhAN-154 at $40^{\circ} \mathrm{C}$ & -775 & 6.5 & -420 & 35 \\
CT with IFKhAN-154 at $60^{\circ} \mathrm{C}$ & -425 & - & -395 & 60 \\
CT with IFKhAN-154 at $80^{\circ} \mathrm{C}$ & -230 & - & -220 & 235 \\
CT with IFKhAN-154 at $100^{\circ} \mathrm{C}$ & -515 & - & -205 & 250 \\
CT with IFKhAN-154 at $120^{\circ} \mathrm{C}$ & -415 & - & -360 & 95 \\
\hline
\end{tabular}

A similar effect was shown by $\mathrm{CT}$ in IFKhAN-154 vapors at $40^{\circ} \mathrm{C}$. The anodic curves nearly coincided with the curves obtained on samples heat-treated without a CIN. CT at higher temperatures led to a significant ennoblement of $E_{0}$ and $E_{\mathrm{br}}$ and complete suppression of active dissolution. The largest ennoblement of $E_{0}$ was observed for IFKhAN-154 films formed upon $\mathrm{CT}$ at $80^{\circ} \mathrm{C}$, while the largest passive region and the ennoblement of $E_{\mathrm{br}}$ were achieved after $\mathrm{CT}$ at $100^{\circ} \mathrm{C}$. A further increase in the $\mathrm{CT}$ temperature $\left(t_{\mathrm{CT}}\right)$ to $120^{\circ} \mathrm{C}$ did not improve the protective effect. Moreover, in this case, a noticeable shift of $E_{\mathrm{br}}$ in the cathodic direction was observed.

Temperature dependences of the protective action of CIN passing through an extremum were also observed previously. The possible reasons for the existence of maxima in the temperature dependences of the protective effect of CIN were discussed elsewhere [13-15]. Most likely, an increase in the protective properties of inhibitors with an increase in $t_{\mathrm{CT}}$ is explained by an increase in their vapor pressure and, as a consequence, an increase in the adsorption on the metal. The descending branch of the dependence is associated with the well-known fact that adsorption decreases with an increase in the adsorbent temperature.

Thus, voltammetric measurements show that CT of steel with a TS12 coating suppressed the active dissolution and stabilized the passive state. These effects are most pronounced at $t_{\mathrm{CT}}=100^{\circ} \mathrm{C}$.

Electrochemical impedance spectroscopy is yet another informative electrochemical non-destructive method of studies. Analysis of Nyquist plots makes it possible to estimate the protective effect of surface films on zinc coatings.

Like in voltammetric tests, the spectrum of steel coated with Ts 12 before TT is virtually identical to the spectrum of Ts 0 zinc. It is described with high accuracy by the classical scheme A (Figure 1) [20]. The values of $n_{\mathrm{dl}}$ (Table 2) are close to 1, which makes it possible to consider $Q_{\mathrm{dl}}$ as the pure double layer capacitance. 


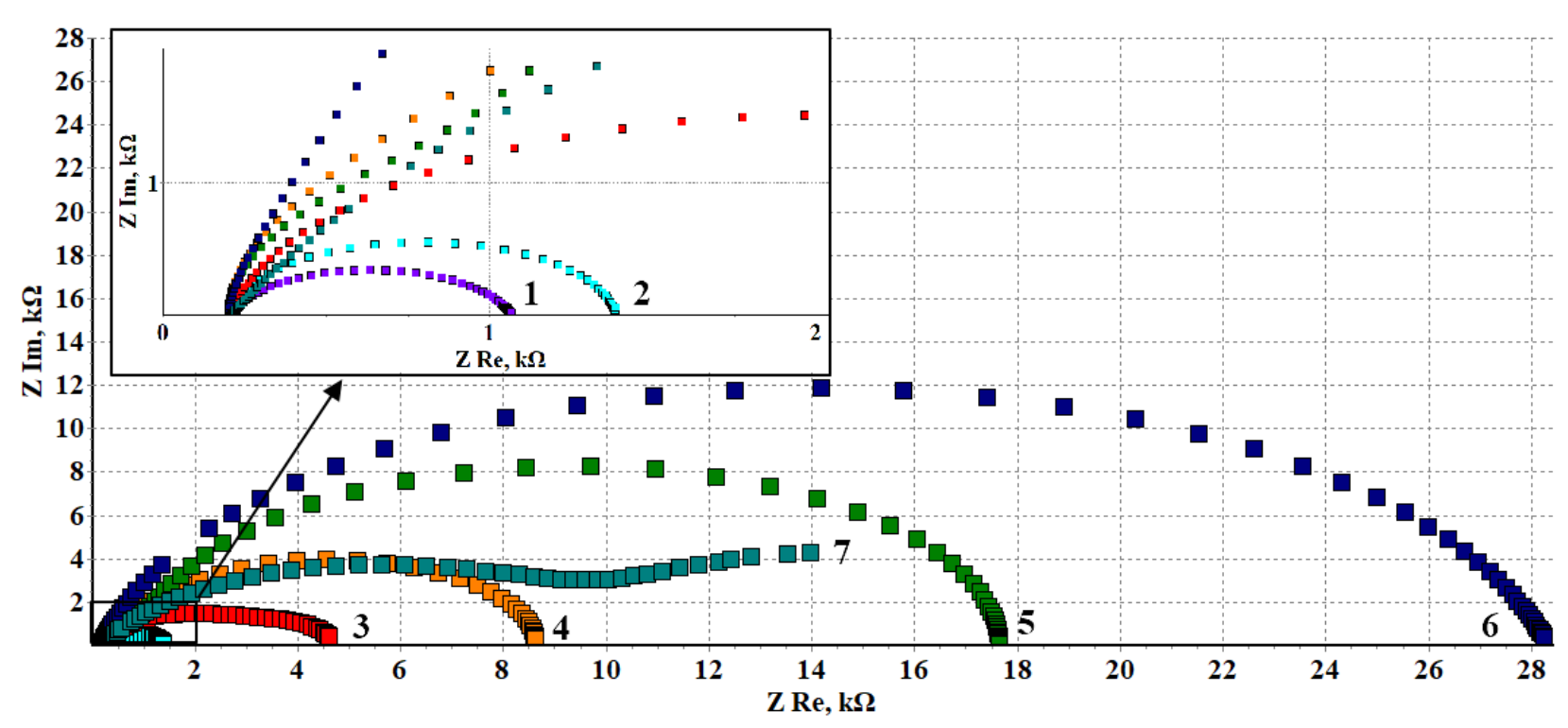

Figure 2. Nyquist plots of steel with Ts12 coating before (1) and after TT without IFKhAN$154\left(2,100^{\circ} \mathrm{C}\right)$ and after $\mathrm{CT}$ in its vapors at $40^{\circ} \mathrm{C}(3), 60^{\circ} \mathrm{C}(4), 80^{\circ} \mathrm{C}(5), 100^{\circ} \mathrm{C}(6)$, and $120^{\circ} \mathrm{C}(7)$. The treatment time was 1 hour. The exposure time of samples in air after TT or CT was 24 hours.

$\mathrm{TT}$ at $100^{\circ} \mathrm{C}$ led to an increase in the hodograph radius, while its shape remained nearly unchanged. After TT, a slight increase in $R_{\mathrm{ct}}$ was observed, probably due to partial blocking of the surface by the oxide. Similarly to the sample in the initial state, the value of $Q_{\mathrm{dl}}$ can be interpreted as the double layer capacitance. In this case, the electrochemically active surface area decreases $c a$. 3-fold.

Table 2. Calculated values of equivalent circuits parameters after treatment of steel with a Ts12 coating under various conditions. The treatment time was 1 hour. The exposure time of samples in air after TT or CT was 24 hours.

\begin{tabular}{ccccccccc}
\hline Treatment conditions & $\begin{array}{c}\boldsymbol{R}_{\mathbf{r}} \\
\mathbf{k} \boldsymbol{\Omega}\end{array}$ & $\boldsymbol{Q}_{\text {sl }}$ & $\boldsymbol{n}_{\mathbf{s l}}$ & $\begin{array}{c}\boldsymbol{R}_{\text {sl }} \\
\mathbf{k} \boldsymbol{\Omega}\end{array}$ & $\boldsymbol{Q}_{\text {dl }}$ & $\boldsymbol{n}_{\mathbf{d l l}}$ & $\begin{array}{c}\boldsymbol{R}_{\mathbf{c t}} \\
\mathbf{k} \boldsymbol{\Omega}\end{array}$ & $\boldsymbol{Z}, \boldsymbol{\%}$ \\
\hline Without treatment & 0.2 & - & - & - & $4.69 \cdot 10^{-5}$ & 0.87 & 0.87 & - \\
\hline TT at $100^{\circ} \mathrm{C}$ & 0.2 & - & - & - & $1.49 \cdot 10^{-5}$ & 0.97 & 1.19 & 26.89 \\
\hline CT with IFKhAN-154 at $40^{\circ} \mathrm{C}$ & 0.2 & $1.92 \cdot 10^{-5}$ & 0.91 & 3.42 & $2.76 \cdot 10^{-4}$ & 1 & 1.08 & 80.67 \\
\hline $\mathrm{CT}$ with IFKhAN-154 at $60^{\circ} \mathrm{C}$ & 0.2 & $5.10 \cdot 10^{-6}$ & 1 & 3.48 & $6.45 \cdot 10^{-6}$ & 1 & 4.96 & 89.69 \\
\hline $\mathrm{CT}$ with IFKhAN-154 at $80^{\circ} \mathrm{C}$ & 0.2 & $9.81 \cdot 10^{-7}$ & 1 & 2.8 & $1.58 \cdot 10^{-7}$ & 1 & 14.65 & 95.01 \\
\hline $\mathrm{CT}$ with IFKhAN-154 at $100^{\circ} \mathrm{C}$ & 0.2 & $2.41 \cdot 10^{-7}$ & 1 & 2.27 & $6.08 \cdot 10^{-7}$ & 0.77 & 25.87 & 96.9 \\
\hline $\mathrm{CT}$ with IFKhAN- 154 at $120^{\circ} \mathrm{C}$ & 0.2 & $6.36 \cdot 10^{-6}$ & 0.78 & 10.4 & $1.76 \cdot 10^{-4}$ & 0.82 & 9.99 & 95.73 \\
\hline
\end{tabular}

CT in IFKhAN-154 vapors led to a greater increase in the hodograph radius and somewhat changed its shape. In this case, the classical Randles scheme (Figure 1A) ceases 
to describe the system adequately. To describe this spectrum correctly, we used the circuit shown in Figure 1B.

$\mathrm{CT}$ at $40^{\circ} \mathrm{C}$ resulted in an increase in the electrochemically active surface area and a certain decrease in the polarization resistance in comparison with the metal heat-treated without a CIN. This can be interpreted as a result of destruction of the surface oxide layer by CIN vapors. Nevertheless, the inhibitor adsorption layers formed within 1 hour of CT had protective properties, as confirmed by the appearance of $R_{\mathrm{sl}}$ in the equivalent circuit.

An increase in $t_{\mathrm{CT}}$ up to $100^{\circ} \mathrm{C}$ increased the hodograph radius significantly. The films formed at $60^{\circ} \mathrm{C}$ or above were relatively uniform, as indicated by the value of $n_{\mathrm{sl}}$. At the same time, the polarization resistance increased and the fraction of electrochemically active zinc surface decreased symbatically with an increase in $t_{\mathrm{C} \text {. }}$. It is essential that, starting from a $t_{\mathrm{CT}}$ of $60^{\circ} \mathrm{C}$, polarization resistance makes the main contribution to the corrosion resistance of the metal. The film resistance nearly does not change, though its thickness increases, judging by the values of $Q_{\mathrm{sl}}$. This allows one to assume that the main contribution to the protective effect is made by the "activation" mechanism related to the polarization resistance value. Surface blocking as an alternative corrosion protection mechanism is associated with the resistance of the surface film, and its contribution is nearly not affected by $t_{\text {Ст. This effect }}$ is probably due to the electrical conductivity and structure of the CIN surface film.

The maximum protection of steel with a Ts12 coating $(Z=96.9 \%)$ was achieved at a $t_{\mathrm{CT}}$ of $100^{\circ} \mathrm{C}$. Like in the voltammetric experiments, a further increase in $t_{\mathrm{CT}}$ resulted in some decrease in the efficiency of chamber protection. In this case, the shape of the hodograph changed significantly: two capacitive semicircles could be clearly distinguished on it. A calculation of the values of these parameters shows an increase in $R_{\mathrm{sl}}$ and a decrease in $R_{\mathrm{ct}}$ in comparison with the previous treatment options, which can be interpreted as an increase in the effect of the blocking mechanism of the CIN. This phenomenon is explained by a very thick and visible CIN layer formed at $120^{\circ} \mathrm{C}$.

Thus, the results of electrochemical impedance spectroscopy confirm the data of voltammetric measurements showing that the CIN stabilizes the passive state of steel with a Ts 12 coating, which is most pronounced upon $\mathrm{CT}$ at $100^{\circ} \mathrm{C}$. $\mathrm{CT}$ at temperatures ranging from 60 to $100^{\circ} \mathrm{C}$ resulted in the formation of films having a mixed activation-blocking mechanism of action. Comparison of $R_{\mathrm{sl}}$ and $R_{\mathrm{ct}}$ allows us to conclude that the activation mechanism prevails.

The results of electrochemical measurements agree with the data of accelerated corrosion tests.

Under salt fog conditions, the first white dots on steel samples with a Ts12 coating appeared by the end of the first test cycle (Table 3). Subsequent exposure of samples in the chamber led to a significant increase in the number of corrosion sites and their area. TT without a CIN did not increase the time of full protection, a change in the nature of corrosion damage, or a slowdown of their propagation. 
$\mathrm{CT}$ in IFKhAN-154 vapors even at $40^{\circ} \mathrm{C}$ increases the time of TS12 full protection by a factor of 2. With an increase in the $t_{\mathrm{CT}}$, the efficiency of CIN films increases and reaches a maximum at $t=100^{\circ} \mathrm{C}$. A further increase in $t$ (up to $120^{\circ} \mathrm{C}$ ) leads to the formation of thick inhibitor films on the surface and a slight decrease in the full protection time. Corrosion sites after CT have the form of separate points probably localized in the defects of the CIN film. With an increase in $t_{\mathrm{CT}}$, the nature of corrosion does not change, but starting from $60^{\circ} \mathrm{C}$, the propagation of corrosion during the tests slows down significantly. The corrosion sites remain point-like for a period of 72 cycles from the time they appeared.

Table 3. Results of accelerated corrosion tests in a neutral salt spray chamber. The treatment time was 1 hour. The exposure time of samples in air after TT or CT was 24 hours.

\begin{tabular}{cc}
\hline Treatment conditions & $\begin{array}{c}\text { Time (cycles) until the first corrosion sites } \\
\text { appear }\end{array}$ \\
\hline Without treatment & 1 \\
TT at $100^{\circ} \mathrm{C}$ without a CIN & 1 \\
IFKhAN- 154 at $40^{\circ} \mathrm{C}$ & 2 \\
IFKhAN- 154 at $60^{\circ} \mathrm{C}$ & 24 \\
IFKhAN- 154 at $80^{\circ} \mathrm{C}$ & 96 \\
IFKhAN- 154 at $100^{\circ} \mathrm{C}$ & 120 \\
IFKhAN-154 at $120^{\circ} \mathrm{C}$ & 96 \\
\hline
\end{tabular}

Thus, the results of corrosion tests fully confirm the conclusions made from electrochemical experiments. CT in the presence of IFKHAN-154 inhibited the initiation of corrosion on zinc plated steel. At the optimal $t_{\mathrm{CT}}$, the time of full protection of Ts12 increased more than by 2 orders of magnitude.

It is important that the formation of anticorrosive adsorption films on steel with a Ts 12 coating occurs not only during the $\mathrm{CT}$, but also, and to a greater extent, during storage of the samples after the CT. In other words, IFKhAN-154 films have a self-organization capability.

The results of voltammetric studies illustrating this statement are shown in Figure 3 and in Table 4. The polarization of samples after $0.5 \mathrm{~h}$ after CT indicates an activation of the anodic dissolution of the metal compared to the samples that did not undergo TT or exposed at $100^{\circ} \mathrm{C}$ without a CIN. This phenomenon manifests itself as an increase in the current density in the region of zinc active dissolution up to $40 \mu \mathrm{A} / \mathrm{cm}^{2}$ along with easier film breakdown. However, after one-hour exposure of cooled samples in air, the situation changed significantly. The $E_{\mathrm{br}}$ values were still shifted cathodically relative to the reference samples, however, the active dissolution of zinc was suppressed completely. A further exposure of steel samples with a Ts 12 coating in air after CT was accompanied by a $E_{\mathrm{br}}$ ennoblement. One day after the CT, the growth of the protective effect of IFKhAN-154 ceased. 


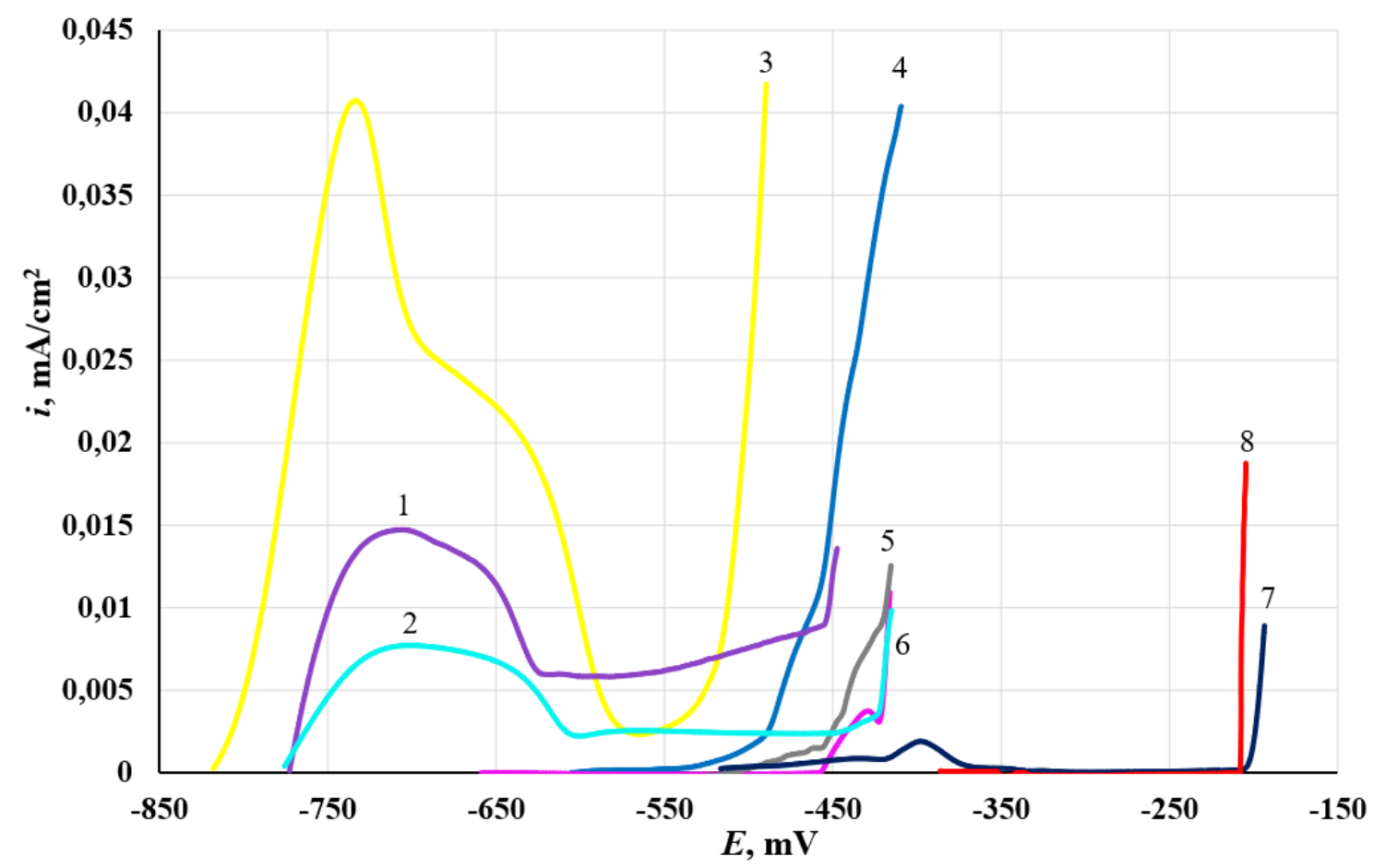

Figure 3. Anodic polarization curves of Ts 12 before treatment (1), after CT at $100^{\circ} \mathrm{C}$ without a CIN (2), and after CT in IFKhAN-154 vapors. Exposure time of samples in air after CT: $3-0.5$ h, $4-1$ h, $5-3$ h, $6-5$ h, $7-24$ h, $8-48$ h. The treatment time was 1 hour.

Table 4. Main characteristics of anodic polarization curves on Ts12 after exposure of samples in air for different periods of time after CT. Treatment time -1 hour, temperature $-100^{\circ} \mathrm{C}$.

\begin{tabular}{|c|c|c|c|c|}
\hline Treatment conditions & $E_{0}, \mathrm{mV}$ & $i, \mu \mathrm{A} / \mathrm{cm}^{2}$ & $E_{\mathrm{br}}, \mathbf{m V}$ & $\Delta E, \mathbf{m V}$ \\
\hline Without treatment & -775 & 14.5 & -455 & - \\
\hline $\mathrm{TT}$ at $100^{\circ} \mathrm{C}$ without a $\mathrm{CIN}$ & -770 & 7.5 & -420 & 35 \\
\hline IFKhAN-154, exposure for $0.5 \mathrm{~h}$ & -820 & 40 & -530 & -75 \\
\hline IFKhAN-154, exposure for $1 \mathrm{~h}$ & -605 & - & -490 & -35 \\
\hline IFKhAN-154, exposure for $3 \mathrm{~h}$ & -505 & - & -455 & 0 \\
\hline IFKhAN-154, exposure for $5 \mathrm{~h}$ & -655 & - & -450 & 5 \\
\hline IFKhAN-154, exposure for $24 \mathrm{~h}$ & -515 & - & -205 & 250 \\
\hline IFKhAN-154, exposure for $48 \mathrm{~h}$ & -386 & - & -210 & 245 \\
\hline
\end{tabular}

The processes of self-organization of IFKhAN-54 surface films are confirmed by electrochemical impedance spectroscopy data (Figure 4 and Table 5). 


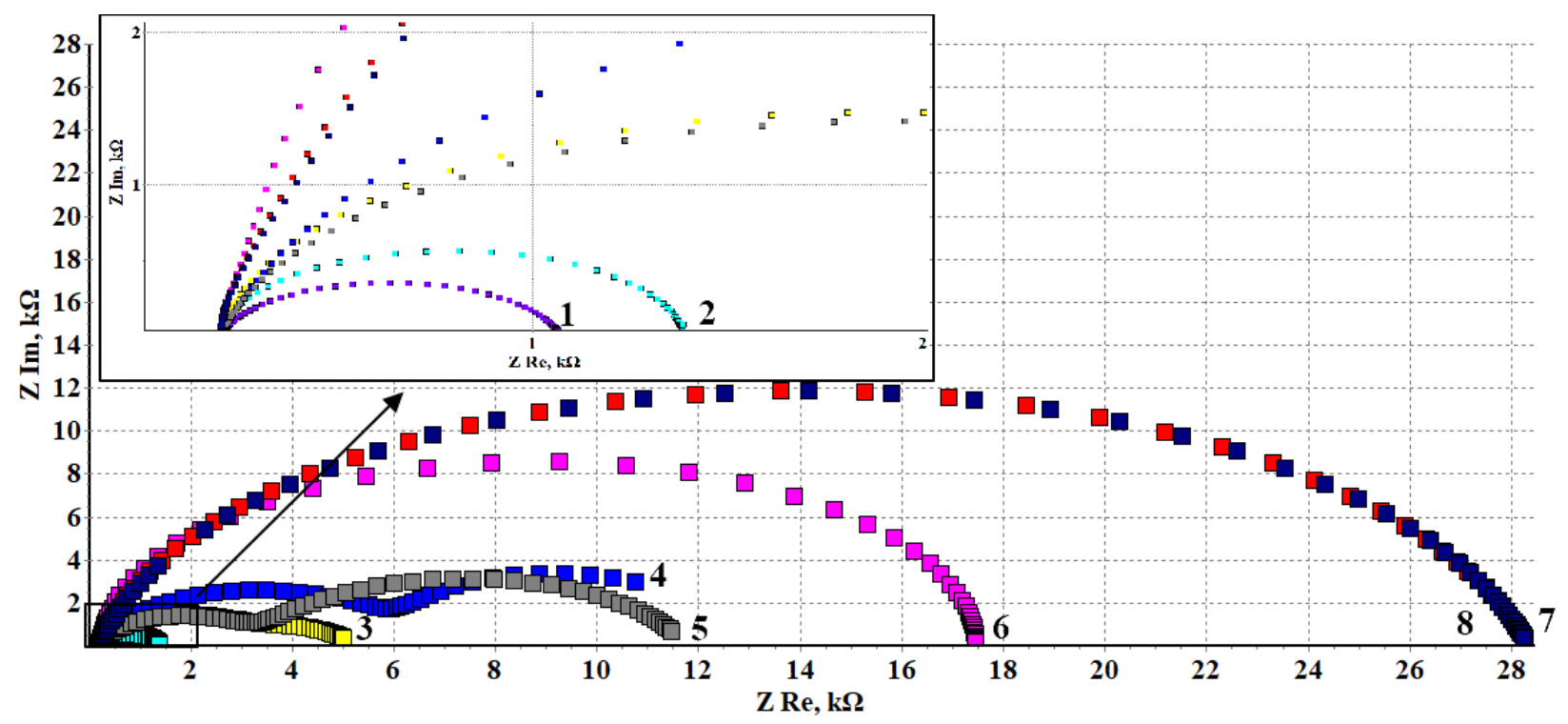

Figure 4. Nyquist plots of steel with Ts 12 coating at different exposure times of samples in air after TT and CT. Exposure time of samples in air after CT: $3-0.5 \mathrm{~h}, 4-1 \mathrm{~h}, 5-3 \mathrm{~h}$, $6-5$ h, $7-24$ h, $8-48$ h. The treatment time was 1 hour.

Table 5. The values of equivalent circuit elements calculated for IFKhAN-154 films on Ts12 at different times of exposure of the samples in air after CT. Treatment time -1 hour, temperature $-100^{\circ} \mathrm{C}$.

\begin{tabular}{cccccccccc}
\hline Treatment conditions & $\begin{array}{c}\boldsymbol{R}_{\mathbf{r}} \\
\mathbf{k} \boldsymbol{\Omega}\end{array}$ & $\boldsymbol{Q}_{\text {sl }}$ & $\boldsymbol{n}_{\text {sl }}$ & $\begin{array}{c}\boldsymbol{R}_{\mathbf{s l}} \\
\mathbf{k} \boldsymbol{\Omega}\end{array}$ & $\boldsymbol{Q}_{\mathbf{d l}}$ & $\boldsymbol{n}_{\text {dl }}$ & $\begin{array}{c}\boldsymbol{R}_{\text {ct }} \\
\mathbf{k} \boldsymbol{\Omega}\end{array}$ & $\boldsymbol{Z}, \boldsymbol{\%}$ \\
\hline No treatment & 0.2 & - & - & - & $4.69 \cdot 10^{-5}$ & 0.87 & 0.87 & - \\
TT at $100^{\circ} \mathrm{C}$ without a CIN & 0.2 & - & - & - & $1.49 \cdot 10^{-5}$ & 0.97 & 1.19 & 26.90 \\
IFKhAN-154, exposure for $0.5 \mathrm{~h}$ & 0.2 & $4.26 \cdot 10^{-6}$ & 0.94 & 3.11 & $1.59 \cdot 10^{-4}$ & 0.75 & 1.92 & 82.70 \\
IFKhAN-154, exposure for 1 h & 0.2 & $4.85 \cdot 10^{-6}$ & 0.88 & 6.27 & $1.54 \cdot 10^{-4}$ & 1 & 6.13 & 93.00 \\
IFKhAN-154, exposure for 3 h & 0.2 & $3.23 \cdot 10^{-7}$ & 0.9 & 3.23 & $1.58 \cdot 10^{-5}$ & 0.8 & 8.33 & 92.45 \\
IFKhAN-154, exposure for 5 h & 0.2 & $8.31 \cdot 10^{-7}$ & 1 & 2.92 & $2.06 \cdot 10^{-7}$ & 1 & 14.33 & 94.95 \\
IFKhAN-154, exposure for 24 h & 0.2 & $2.41 \cdot 10^{-7}$ & 1 & 2.27 & $6.08 \cdot 10^{-7}$ & 0.78 & 25.87 & 96.90 \\
IFKhAN-154, exposure for 48 h & 0.2 & $2.52 \cdot 10^{-7}$ & 1 & 2.38 & $6.18 \cdot 10^{-7}$ & 0.78 & 25.79 & 96.91 \\
\hline
\end{tabular}

Regardless of the time the samples are exposed in air after cooling, the $n_{\mathrm{sl}}$ value was in the range of $0.88-1$, suggesting that the films are uniform. A decrease in $Q_{\text {sl }}$ values is due to changes in the CIN films in the course of exposure, possibly reorganization of the surface layers and/or formation of IFKhAN-154 compounds with zinc, as well as oxidation with atmospheric oxygen.

The hodographs of samples exposed in air for $0.5,1$, or $3 \mathrm{~h}$ after CT have two distinct semicircles, one of which in the high-frequency region characterizes the surface film, whereas the other one in the low-frequency region characterizes the double electric layer. 
Such distinct semicircles are due to low $R_{\mathrm{ct}}$ values that are comparable to $R_{\mathrm{sl}}$ values. As the time of exposure of samples increases to 5 hours or more, $R_{\mathrm{ct}}$ increases considerably, so the shape of Nyquist plots changes: the high-frequency semicircle becomes less distinct.

With an increase in exposure time, the polarization resistance also increases, while the fraction of electrochemically active metal surface $\left(Q_{\mathrm{dl}}\right)$ decreases. In this case, already after $5 \mathrm{~h}$ of exposure of treated samples in air, the $R_{\mathrm{ct}}$ values are significantly higher than the $R_{\mathrm{sl}}$ values, which leads to a change in the hodograph shape - they turn to distorted semicircles. This can be attributed to the formation of dense surface films chemically bound to the Ts 12 surface.

This is clearly demonstrated by the change in $Z$ with an increase in the exposure of coated steel samples in air after CT. It is evident that the $Z$ values grow symbatically with exposure time in the range from 0.5 to 24 hours. A further increase in the exposure time of the samples in air did not increase the protective aftereffect of the adsorption films. The $Z$ values stabilized at the level of $95-96 \%$.

The results of electrochemical tests and impedance spectroscopy were confirmed by accelerated corrosion tests in a salt fog chamber (Table 6).

Table 6. Results of accelerated corrosion tests of IFKhAN-154 films at different times of exposure of samples in air after heat treatment. Treatment time -1 hour, temperature $-100^{\circ} \mathrm{C}$.

\section{CT conditions}

Time (cycles) until the first corrosion sites appear

No treatment

TT at $100^{\circ} \mathrm{C}$ without a CIN

IFKhAN-154, exposure for $0.5 \mathrm{~h}$

IFKhAN-154, exposure for $1 \mathrm{~h}$

IFKhAN-154, exposure for $3 \mathrm{~h}$

IFKhAN-154, exposure for $5 \mathrm{~h}$

IFKhAN-154, exposure for $24 \mathrm{~h}$

IFKhAN-154, exposure for $48 \mathrm{~h}$

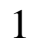

1

2

48

56

100

120

120

With an increase in the exposure time of samples after CT from $0.5 \mathrm{~h}$ to $24 \mathrm{~h}$, the time of full protection increases 60-fold. A longer exposure of samples in air did not increase their corrosion resistance.

To understand the chamber protection processes, including the self-organization of surface films, a more detailed study of this process by spectral methods is required. However, even the available data suggest the following general picture of the process that does not contradict the experimental data. Upon CT of steel with a Ts12 zinc coating in IFKhAN-154 vapors, the inhibitor is physically adsorbed on the sample surface. As a liquid acid, 
IFKhAN-154 begins to react with the surface oxide and with zinc itself during the CT. This process results in poorly soluble salts that ensure the metal protection. The reaction continues after the end of the CT when the samples are kept in air. It is accompanied by changes in the thickness and uniformity of the coating, as well as an increase in the protective properties of the surface films. In about a day, IFKhAN-154 present on the surface is exhausted, and the growth of the protective effect of the surface layers ceases.

\section{Conclusions}

1. The IFKhAN-154 chamber inhibitor provides efficient protection of zinc plated steel against corrosion and anodic dissolution.

2. The optimum temperature of one-hour treatment chamber of zinc plated steel with IFKhAN-154 inhibitor is $100^{\circ} \mathrm{C}$.

3. Adsorption films of IFKhAN-154 have a self-organizing capability. After zinc plated steel samples treated with this inhibitor are exposed in air, their corrosion resistance increases.

\section{References}

1. V.V. Okulov, Zinc plating. Technique and technology, Moscow, Globus, 2008, 252 pp. (in Russian).

2. V.A. Kozlov and M.O. Mesnik, Basics of corrosion and protection of metals, Ivanovo, IGKhTU, 2011, 177 pp. (in Russian).

3. Corrosion. Manual, Ed. L.L. Shreir, Moscow, Metallurgiya, 1981, 164 pp. (in Russian; translated from English).

4. K. Kreislova and D. Knotkova, The results of 45 years of atmospheric corrosion study in the Czech Republic, Materials, 2017, 10, no 4, 394. doi: 10.3390/ma10040394

5. N.T. Kudryavtsev and A.A. Nikiforova, Proceedings of NITO "Zinc and cadmium in corrosion protection technology”, Goskhimizdat, 1941, 83 pp. (in Russian).

6. R.R. Sharmaitis, Zhurnal vsesoyuznogo khimicheskogo obshchestva im. D.I. Mendeleeva, 1988, 33, no. 3, 325 pp. (in Russian).

7. Federal sanitary regulations, norms and hygienic regulations, GN 11725-98 (in Russian).

8. W. Eckles and R. Frischauf, Plating and Surface Finishing, Jan. 2007, 27.

9. N.N. Andreev, O.A. Goncharova, Yu.I. Kuznetsov and A.Yu. Luchkin, Method for protection of metals from atmospheric corrosion, RF Patent 264935402.04 .2018 (in Russian).

10. A.Yu. Luchkin, O.A. Goncharova, N.N. Andreev, Yu.I. Kuznetsov and N.P. Andreeva, Copper protection by treatment with vepors of low volatile inhibitors at elevated temperature, Korroz.: Mater., Zashch. (Corrosion: materials, protection), 2017, no. 11, 25-31 (in Russian). 
11. A.Yu. Luchkin, O.A. Goncharova, N.N. Andreev and Yu.I. Kuznetsov, Steel protection by treatment with vapors of octadecylamine, 1,2,3-benzotriazole, and their mixture at elevated temperature, Korroz.: Mater., Zashch. (Corrosion: materials, protection), 2017, no. 12, 20-26 (in Russian).

12. O.A. Goncharova, Yu.I. Kuznetsov, N.N. Andreev, A.Yu. Luchkin, N.P. Andreeva and D.S. Kuznetsov, A new corrosion inhibitor for zinc chamber treatment, Int. J. Corros. Scale Inhib., 2018, 7, no. 3, 340-351. doi: 10.17675/2305-6894-2018-7-3-5

13. A.Yu. Luchkin, O.A. Goncharova, I.A. Arkhipushkin, N.N. Andreev and Yu.I. Kuznetsov, The effect of oxide and adsorption layers formed in 5Chlorobenzotriazole vapors on the corrosion resistance of copper, J. Taiwan Inst. Chem. Eng., 2020, 117, 231-241. doi: 10.1016/j.jtice.2020.12.005

14. O.A. Goncharova, A.Yu. Luchkin, Yu.I. Kuznetsov and N.N. Andreev, Vapor-phase protection of zinc from atmospheric corrosion by low volatile organic inhibitors, Korroz.: Mater., Zashch. (Corrosion: materials, protection), 2018, no. 8, 8-13 (in Russian).

15. O.A. Betretdinova, A.Yu. Luchkin, O.A. Goncharova, N.N. Andreev, Chamber protection of zinc plated steel. 1. Screening of the efficiency of zinc and steel corrosion inhibitors, Korroz.: Mater., Zashch. (Corrosion: materials, protection), 2020, no. 7, $33-$ 37 (in Russian). doi: 10.31044/1813-7016-2020-0-7-25-32

16. GOST (USSR State Standard) 9.306-85, Unified system of protection against corrosion and aging. Metallic and non-metallic inorganic coatings. Designations (in Russian).

17. V.M. Rudoi, A.A. Trofimov, M.V. Anan'ev, N.I. Ostanin, A.B. Darintseva, T.N. Ostanina and V.S. Nikitin, Methods of Calculation and Experimental Determination of Electrochemical System Parameters, Ekaterinburg, Urals University Press, 2019 (in Russian).

18. W. Shan, M. Xiao-Ze, M. Chun-Hui, Z. Xin-Xin and D. Ze-Hua, Inhibition of 2-phenyl imidazoline on chloride-induced initial atmospheric corrosion of copper by quartz crystal microbalance and electrochemical impedance, Corros. Sci., 2020, 170, 108692 doi: 101016/jcorsci2020108692

19. D. Wang, B. Xiang, Y. Liang, S. Song and C. Liu, Corrosion control of copper in $3.5 \mathrm{wt} \% \mathrm{NaCl}$ Solution by Domperidone: Experimental and Theoretical Study, Corros. Sci., 2014, 85, 77-86.

20. R. Hsissou, F. Benhiba, O. Dagdag, M. Bouchti, K. Nouneh, M. Assouag, S. Briche, A. Zarrouk and A. Elharfi, Development and potential performance of prepolymer in corrosion inhibition for carbon steel in $10 \mathrm{M} \mathrm{HCl}$ : Outlooks from experimental and computational investigations, J. Colloid Interface Sci., 2020, 574, 43-60. doi: 10.1016/j.jcis.2020.04.022 